\title{
Pancreatic Enzymes Activity under the Conditions of Acute Stress and Melanin Administration Depending on the Stress Resistance
}

\author{
Nataliya Slobodyanyk ${ }^{1}$, Tetyana Beregova ${ }^{2}$ and Karine Neporada ${ }^{1}$ \\ 1. Ukrainian Medical Stomatological Academy, Poltava 36000, Ukraine \\ 2. Taras Shevchenko National University of Kyiv, Kyiv 02140, Ukraine
}

\begin{abstract}
Total proteolytic, antitrypsic, amylase and lypolytic activity was studied on animals subjected to acute stress simulation. Acute stress results in the development of imbalance of protease inhibitors potential as well as in the increase of amylase and lipase activity in the pancreas of the rats. Prior melanin administration in acute stress leads to a decrease in the activity of amylase and lipase, and an increase of total activity of protease inhibitors, that demonstrates stress-protective melanin effect produced on the pancreas.
\end{abstract}

Key words: Pancreas, stress resistance, acute stress, enzymes, melanin.

\section{Introduction}

Currently, society living in the "western" way has faced the increase in prevalence of lifestyle diseases which share psychological stress as common pathophysiological basis. Chronic adverse effects experienced by humans in conditions of anthropogenic pressing, social instability, and intense rhythm of life can be both the main and additional etiological factor for many diseases. Therefore, searching for adaptogens capable of providing protection against stress is very relevant today. Melanin is though as one of them. Recent studies have confirmed stress protective effect of melanin [1-5]. Manifestation of melanin protective properties in stress is associated with increasing level of nitric oxide, which plays an important role in cytoprotection [6]. Anti-stress effect produced by melanin upon the gastric mucosa in rats is completely or partially determined by the activation of PPAR $\gamma$. It is known the GW9662, an antagonist of PPAR $\gamma$, eliminates the

Corresponding autor: Karine Neporada, professor, research field: acute stress. E-mail: neporada_69@mail.ru. protective effect produced by melanin on stress-induced gastric mucosa lesions in rats that strongly suggest the cytoprotevtive properties of melanin are determined by the stimulation of peroxisome proliferation activated receptors Gamma [7]. There is increasing evidence for melanin produced by Nadsoniellanigra strain $X-1$ to reduce the corticosterone concentration in the blood of rats in stress syndrome [4].

In Ukraine, diseases of digestive system are ranked as the fourth most prevalent causes of death, especially in men. During 2006-2010 the prevalence of digestive diseases increased by $5.76 \%$, in which the proportion of pancreatic diseases makes up $10.92 \%$ [8]. In Ukraine, mortality in chronic pancreatitis is ranged from 3 to 9 cases per 100,000 populations [9], and acute pancreatitis is the third most prevalent surgical diseases. The incidence of acute pancreatitis, for instance, in the USA is $49.5 \%$, in Finland is $73.4 \%$ per 100,000 populations, and the mortality rate is about $11.9 \%$ [10].

One of the consequences of stress factors is the activation of cytolysis and change of enzyme activity 
of the pancreas. In particular, the activation of pancreatic proteases induces the degeneration (autolysis) of pancreas, acute pancreatitis as well as the damage of nearby organs. Previously, some reports demonstrated convincingly that pancreas as a main source of aggressive hydrolyses played an important role in tissue damage during the catabolic phase of stress syndrome [11]. Thus, our study is aimed to investigate differences of pancreatic enzyme activity depending on individual and typological characteristics and melanin stress-protecting properties in the pancreas of rats.

\section{Methods}

The study involved 84 Wistar male rats weighing 180-220 g. All manipulations on animals were carried out in accordance with "European convention for the protection of vertebrate animals used for experimental and other scientific purposes" (Strasbourg, 1986). To simulate acute immobilization stress the animals were fixed lying on the back as long as 3 hrs [12]. Stress resistance of the animals was determined by means of open-field test and variable data obtained. The test animals, which showed rapid adaptation, low indicators of motor activity, exploratory behavior, and vegetative balance were rated as stress-resistant ones, while the rats with low adaptation, high parameters of motor activity, exploratory behavior, and vegetative balance were described as a stress-susceptible group [13]. The control group was made up of the animals of the respective type. The rats were sacrificed by phlebotomy carried out under hexenal anesthesia (50 $\mathrm{mg} / \mathrm{kg}$ ).

The pancreas of the animals was the object of research to investigate the total proteolytic [14], antitrypsic [15], amylase (EC: 3.2.1.1) (kit " $\alpha$-amylase", "Fylyzyt-Diagnosis", Ukraine) and lypolytic activity (EC: 3.1.1.3) [16]. Thirty minutes prior modeling acute stress the rats were administered synthetic melanin (Sigma) in a dose of $5 \mathrm{mg} / \mathrm{kg}$ intragastrically. The obtained data were processed with generally accepted method of variation statistics.

\section{Results and Discussion.}

This study has shown that under acute stress the total proteolytic activity in the pancreas probably increases in 1.9 times compared with the animals of control group of the respective type of response (Table 1). In these conditions, the activation of proteolytic processes in the pancreas of stress-resistant animals is not observed compared with the control group (Table 1). It is necessary to emphasize the analysis of enzyme proteolytic activity as well as the investigation of total antiproteolytic activity is important in the assessment of protease inhibitors potential. We have revealed that under acute stress simulation the stress-susceptible animals are observed to demonstrate likely decrease in total antiproteolytic activity in 1.1 times compared with the control group of the respective type (Table 2). No significant changes of these indicators in the stress-resistant animals are observed (Table 2).

Thus, the stress-susceptible animals while being exposed to acute stress show the activation of proteolytic processes against the declined activity of

Table 1 The total proteolytic activity in pancreas of the rats with different resistance to stress, $\mu \mathrm{mol} / \mathrm{g}^{*}(\mathrm{M} \pm \mathbf{m})$.

\begin{tabular}{lll}
\hline Groups of animals & Stress-resistant & Stress-susceptible \\
\hline 1. Control & $1.16 \pm 0.26(\mathrm{n}=11)$ & $0.98 \pm 0.16(\mathrm{n}=11)$ \\
2. Acute stress & $1.43 \pm 0.40(\mathrm{n}=11)$ & $1.87 \pm 0.14(\mathrm{n}=11)$ \\
3. Melanin & $1.07 \pm 0.04(\mathrm{n}=7)$ & $0.85 \pm 0.02(\mathrm{n}=6)$ \\
4. Melanin + acute stress & $1.02 \pm 0.08(\mathrm{n}=8)$ & $1.01 \pm 0.05(\mathrm{n}=7)$ \\
5. Placebo + acute stress & $1.68 \pm 0.20(\mathrm{n}=5)$ & $1.93 \pm 0.14(\mathrm{n}=7)$ \\
& $\mathrm{P}_{1-2}>0.05 ; \mathrm{P}_{2-3}>0.05 ;$ & $\mathrm{P}_{1-2}<0.05 ; \mathrm{P}_{2-3}<0.05 ;$ \\
Statistical index & $\mathrm{P}_{1-3}>0.05 ; \mathrm{P}_{2-4}>0.05 ;$ & $\mathrm{P}_{1-3}>0.05 ; \mathrm{P}_{2-4}<0.05 ;$ \\
& $\mathrm{P}_{1-4}>0.05 ; \mathrm{P}_{2-5}>0.05 ;$ & $\mathrm{P}_{1-4}>0.05 ; \mathrm{P}_{2-5}>0.05 ;$ \\
\hline
\end{tabular}

$\mathrm{n}$-number of animals. 
Table 2 Anti-proteolytic activity in pancreas of rats with different resistance to stress, $\mathrm{g} / \mathrm{kg},(\mathrm{M} \pm \mathrm{m})$.

\begin{tabular}{lll}
\hline Groups of animals & Stress-resistant & Stress-susceptible \\
\hline 1. Control & $56.07 \pm 1.47(\mathrm{n}=11)$ & $55.24 \pm 0.79(\mathrm{n}=11)$ \\
2. Acute stress & $53.65 \pm 1.62(\mathrm{n}=11)$ & $51.61 \pm 1.23(\mathrm{n}=11)$ \\
3. Melanin & $59.38 \pm 0.90(\mathrm{n}=7)$ & $57.50 \pm 0.66(\mathrm{n}=6)$ \\
4. Melanin + acute stress & $55.46 \pm 1.12(\mathrm{n}=8)$ & $52.76 \pm 0.90(\mathrm{n}=7)$ \\
5. Placebo + acute stress & $50.90 \pm 1.47(\mathrm{n}=5)$ & $49.14 \pm 0.53(\mathrm{n}=7)$ \\
& $\mathrm{P}_{1-2}>0.05 ; \mathrm{P}_{2-3}<0.05 ;$ & $\mathrm{P}_{1-2}<0.05 ; \mathrm{P}_{2-3}<0.05 ;$ \\
Statistical index & $\mathrm{P}_{1-3}>0.05 ; \mathrm{P}_{2-4}>0.05 ;$ & $\mathrm{P}_{1-3}<0.05 ; \mathrm{P}_{2-4}>0.05 ;$ \\
& $\mathrm{P}_{1-4}>0.05 ; \mathrm{P}_{2-5}>0.05 ;$ & $\mathrm{P}_{1-4}<0.05 ; \mathrm{P}_{2-5}>0.05 ;$ \\
\hline
\end{tabular}

$\mathrm{n}$-number of animals.

protease inhibitors. This implies that the protease inhibitors imbalance develops by decompensated type [17].

Protease activity determined following the administration of melanin $30 \mathrm{~min}$. before acute stress simulation is in 1.14 times lower compared with this in the intact animals of the stress-resistant type and is in 1.03 times lower than in the respective control rats of the stress-susceptible type. Melanin administration 30 min. prior acute stress significantly reduces the total proteolytic activity in 1.40 times in the stress-resistant animals and significantly reduces, in 1.85 times, in the stress-susceptible animals compared with the stressed rats of the respective type. Under the same conditions the previous administration of placebo results in the increase of proteolytic activity in 1.17 times in the stress-resistant rats and in 1.03 times in the stress-susceptible animals compared with the control groups of respective types. It has been found out the total proteolytic activity during the prior introduction of melanin to stressed rats significantly increases in 1.65 times in the stress-resistant rats and in 1.91 times in the stress-susceptible rats compared with the rats of the respective types of stress resistance which received placebo prior the experiment (Table $1)$.

Introduction of melanin $30 \mathrm{~min}$. before the acute stress modeling increases total anti-proteolytic activity in 1.03 times in the stress-resistant animals and in 1.02 times in the stress-susceptible animals compared with the stressed rats of the respective types of stress resistance. We have revealed that under the same conditions the introduction of placebo results in the reduced activity of inhibitors of proteolytic enzymes in 1.05 times in the rats of stress-nonresistant type and in 1.05 times in the stress-susceptible animals compared with the animals of respective type (Table 2).

Lipase and amylase are indicator enzymes that reflect the development of pancreatic cytolytic syndrome in different conditions [18].

We have ascertained that under the conditions of the developing stress syndrome against the increasing activation of proteolytic processes leading to accelerated catabolism of biomolecules and labilization of lysosomes, there is a significant increase, in 1.09 times, of amylase activity in the pancreas of the stress-susceptible animals compared with the control animals of the respective type (Table 3 ). The analysis of pancreatic amylase activity in the stress-resistant animals shows no significant changes (Table 3). Melanin administration prior the acute stress modeling significantly reduces amylase activity compared with the control animals of the stress-resistant type and is in 1.02 times lower than in the respective control rats of the stress-susceptible type. Introduction of placebo 30 minutes before the animals were subjected to acute stress leads to increased amylase activity in 1.01 times in stress-resistant animals and likely increase in 1.09 times in the stress-susceptible rats compared with the corresponding control animals. Administration of 
Table 3 The activity of $\alpha$-amylase in pancreas of rats with different resistance to stress, $\mathrm{g} / \mathrm{g}^{*} \mathbf{h}(\mathbf{M} \pm \mathbf{m})$.

\begin{tabular}{lll}
\hline Groups of animals & Stress-resistant & Stress-susceptible \\
\hline 1. Control & $21.44 \pm 0.09(\mathrm{n}=8)$ & $20.57 \pm 0.2(\mathrm{n}=8)$ \\
2. Acute stress & $21.79 \pm 0.21(\mathrm{n}=8)$ & $22.38 \pm 0.34(\mathrm{n}=8)$ \\
3. Melanin & $19.98 \pm 0.31(\mathrm{n}=7)$ & $19.00 \pm 0.28(\mathrm{n}=6)$ \\
4. Melanin + acute stress & $20.35 \pm 0.20(\mathrm{n}=8)$ & $20.18 \pm 0.19(\mathrm{n}=7)$ \\
5. Placebo + acute stress & $21.62 \pm 0.19(\mathrm{n}=5)$ & $22.38 \pm 0.75(\mathrm{n}=7)$ \\
& $\mathrm{P}_{1-2}>0.05 ; \mathrm{P}_{2-3}<0.05 ;$ & $\mathrm{P}_{1-2}<0.05 ; \mathrm{P}_{2-3}<0.05 ;$ \\
Statistical index & $\mathrm{P}_{1-3}<0.05 ; \mathrm{P}_{2-4}<0.05 ;$ & $\mathrm{P}_{1-3}<0.05 ; \mathrm{P}_{2-4}<0.05 ;$ \\
& $\mathrm{P}_{1-4}<0.05 ; \mathrm{P}_{2-5}>0.05 ;$ & $\mathrm{P}_{1-4}>0.05 ; \mathrm{P}_{2-5}>0.05 ;$ \\
\hline
\end{tabular}

Table 4 The activity of lipase in pancreas of rats with different resistance to stress, $\mu \mathrm{mol} / \mathrm{g}^{*} \mathrm{~min}(\mathrm{M} \pm \mathrm{m})$.

\begin{tabular}{lll}
\hline Groups of animals & Stress-resistant & Stress-susceptible \\
\hline 1. Control & $12.75 \pm 1.18(\mathrm{n}=8)$ & $12.7 \pm 0.97(\mathrm{n}=8)$ \\
2. Acute stress & $13.38 \pm 3.02(\mathrm{n}=8)$ & $23.2 \pm 1.16(\mathrm{n}=8)$ \\
3. Melanin & $9.36 \pm 1.53(\mathrm{n}=7)$ & $8.11 \pm 1.06(\mathrm{n}=6)$ \\
4. Melanin + acute stress & $11.33 \pm 0.87(\mathrm{n}=8)$ & $11.66 \pm 0.46(\mathrm{n}=7)$ \\
5. Placebo + acute stress & $16.24 \pm 1.94(\mathrm{n}=5)$ & $24.32 \pm 1.13(\mathrm{n}=7)$ \\
& $\mathrm{P}_{1-2}>0.05 ; \mathrm{P}_{2-3}>0.05 ;$ & $\mathrm{P}_{1-2}<0.05 ; \mathrm{P}_{2-3}<0.05 ;$ \\
Statistical index & $\mathrm{P}_{1-3}>0.05 ; \mathrm{P}_{2-4}>0.05 ;$ & $\mathrm{P}_{1-3}<0.05 ; \mathrm{P}_{2-4}<0.05 ;$ \\
& $\mathrm{P}_{1-4}>0.05 ; \mathrm{P}_{2-5}>0.05 ;$ & $\mathrm{P}_{1-4}>0.05 ; \mathrm{P}_{2-5}>0.05 ;$ \\
\hline
\end{tabular}

melanin before the acute stress probably lowers amylolytic activity in the stress-resistant animals in 1.07 times and decreases amylase activity in the stress-susceptible animals likely in 1.11 times compared with the rats of the respective type. Amylolityc activity under the prior administration of melanin to the stressed rats is significantly lower in 1.06 times in the stress-resistant rats and probably lower in 1.11 times in the stress-susceptable rats compared with the rats which were administered with placebo before the stress simulation (Table 3).

Thus, we observe significant increase in the amylolytic activity in the pancreas of the stress-susceptible animals in the conditions of acute stress.

The study of pancreatic lipolytic activity in both types of animals allows us to find out the probable increase of this indicator in 1.8 times only in the animals susceptible to acute stress compared with the corresponding control animals (Table 4). Under these conditions, the activity of lipase in the pancreas of the stress-resistant animals does not differ from the controls (Table 4).
When melanin is administered 30 minutes before the simulation of acute stress, lipolytic activity is in 1.13 times lower than in the control animals of the stress-resistant type and in 1.09 times lower than in the rats of stress-susceptible type. Whereas the administration of placebo 30 minutes before the modeled acute stress leads to an increase of amylase activity in 1.27 times in the stress-resistant animals and the likely growth of this indicator is in 1.91 times in the stress-susceptible rats compared with the control animals of the respective type of stress resistance.

Administration of melanin before acute stress reduces lipolytic activity in 1.18 times in the stress-resistant animals and significantly decreases twofold in the stress-susceptible animals compared with the respective stressed animals. The activity of pancreatic lipase under the administration of melanin before acute stress significantly decreases in 1.43 times in the stress-resistant rats and significantly decreases in 2.09 times in the stress-susceptible rats in comparison with the rats of the respective type of stress resistance which received placebo before the 
experiment (Table 4).

\section{Conclusions}

Thus, under the conditions of acute stress the development of protease inhibitors imbalance as well as an increase in amylase and lipase activity is evident. Prior administration of melanin against the acute stress results in a decrease in the activity of proteases, amylase, lipase, and the increase in the total antitryptic activity that vindicates stress-protective action produced by melanin upon the pancreas.

\section{References}

[1] Zherebin, U. L., Bondarenko, N. A., Makan, S. U., Phinnik, V. P., Klemanova, N. N., Malikova, L. A., Bogatskiy, A. V., and Valdman, A. V. 1984. "Pharmacological Properties of Enomelanins Pigments." Reports of AMS of Ukraine 3: 64-8. (in Russian)

[2] Ryzhova, G. L., Cravtsova, S. S., Matasova, S. A., Gribel, N. V., and Dychco, K. A. 1997. "Chemical and Pharmacological Properties of Dry Chaga Extract." Chem-Pharm. J. 10 (31): 44-7. (in Russian)

[3] Savitskiy, Ya. M. 2002. "The Influence of Melanin on the Gastric Secretion, Processes of Cytoprotection and Motility of Proximal Part of Digestive System: Dissertation." Ph.D. thesis, Danylo Halytsky Lviv National Medical University Lviv. (in Ukrainian)

[4] Chizhanska, N. V. 2007. "Blood Cortisole Levels in Rats before and after Stress against the Action of Melanin." Bulletin of Problems in Biology and Medicine 1: 40-4. (in Ukrainian)

[5] Mimura, T., Maeda, K., Oda, Y., Terada, T., Yoshida, K., and Aonuma, S. H. 1985. "Studies on Biological Activities of Melanin from Marine Animals. IV. Influence of Fr. SM II (Squid Melanin) on a High Molecular Glycoprotein (Peak I) Level in Rat Gastric Mucosa, and Properties of Peak I as a Gastric Mucosal Defensive Factor." Chem. Pharm. Bull. (Tokyo) 5 (33): 2061-8.

[6] Chizhanska, N. V. 2005. "Role of NO in Cytoprotective Action of Melanin upon the Gastric Mucosa." Bulletin of Problems in Biology and Medicine 3: 56-9. (in Ukrainian)

[7] Chizhanska, N. V. 2011. "Study on Mechanisms of
Antistress Action Produced by Melanin.” Ph.D. thesis, Taras Shevchenko National University of Kyiv. (in Ukrainian)

[8] Anishchenko, O. V. 2011. "Medical and Demographic Situation and Organization of Medical Care for Population in 2010." Kyiv, Ministry of Healthcare of Ukraine. (in Ukrainian)

[9] Gubergrits, N. B. 2009. "Famotidine in the Treatment of Chronic Pancreatitis." Contemporary Gastroenterology 2: 72-80. (in Russian)

[10] Vasylchenko, S. L., Pleten, V. A., Konyk, Yu. M., Matviychuk, M. S., Soloschuk, M. A., Soloschuk, P. V., and Dykun, I. N. 2010. "Experience in the Treatment of Severe Acute Pancreatitis in Dwellers of Dniprodzerzhinsk." Emergency Medicine 5 (30): 61-3. (in Russian)

[11] Vakulenko, S. V. 1998. "Peculiarites of Hydrolitic Enzymes Activity of Pancreas under Acute Stress and Introduction of Thymopentin and Contrycal" Ph.D. thesis, National University of Life and Environmental Sciences of Ukraine. Kyiv. (in Russian)

[12] Selye, Hans. 1960. "Esseys on the Adaptation Syndrome. Moscow.” Medicina. (in Russian)

[13] Mayorov, O. U. 1988. "Neyrodinamic Structure of Systemic Mechanisms of Resistance to Emotional Stress.” M.D. thesis, The Institute of General Pathology and Pathophysiology, Moscow. (in Russian)

[14] Ugolev, A. M., Iezuitova, N. N., Masevich, H. S., Nadirova, T. Ya., and Timopheeva, N. M. 1969. Study of the Digestive Tract in Humans. Saint Petersburg: Science. (in Russian)

[15] Veremeyenko, K. N., Goloborodko, O. P., Kizim, A. I. 1988. Proteolysis in Normal and Pathological Conditions. Kiev: Health. (in Russian)

[16] Menshikov, V. V., Delektorskaya, L. N., Zolotinskaya, R. P., Andreeva, Z. M., Ankirskaya, A. S., Balachovskiy, I. S., Belocrinitskiy, D. V., Voropaeva, S. D., Garanina, E. N., Lukicheva, T. I., Pletneva, N. G., and Smolyanitskiy, A. Y. 1987. Laboratory Methods in the Clinic. Moscow: Medicine. (in Russian)

[17] Fomochkina, I. I. 2012. "Pathogenetic Role of Proteinase Inhibitor System in the Development of Local and Systemic Pathology. "Pathologia. 2 (25): 50-4. (in Russian)

[18] Degtyareva, I. I. 1999. Diseases of Digestive System Organs. Kiev: Demos. (in Russian) 